\title{
O conceito de individuação de Gilles Deleuze: estudo introdutório sobre seu recurso a Espinosa. ${ }^{1}$
}

Bruna Martins Coelho

\section{Resumo:}

O objeto deste estudo é o conceito de 'individuação' na filosofia de Gilles Deleuze a partir de sua interpretação da Ética de Espinosa. A teoria da individuação, um dos eixos condutores da experiência intelectual do filósofo francês, recebe seus primeiros contornos já em Empirismo e subjetividade: ensaio sobre a natureza humana segundo Hume, pois é a crítica da noção de sujeito o primeiro passo que a torna possível. Mas será em seus estudos sobre Espinosa que poderemos ver seu acabamento, com uma compreensão do indivíduo como um processo, como diferença em relação a si mesmo, como aberto para o fora que lhe constitui: melhor seria pensar em pré-individualidades. A diferença é compreendida no interior da imanência por meio de conceitos como 'potência', 'quantidade intensiva' e 'afeto'. Abordaremos, especificamente, a compilação de aulas recémeditada sob o nome En medio a Espinosa, pois esta comunicação é uma introdução a esta temática e os textos de aula possuem um caráter didático pouco encontrado na obra do autor. Aponta-se, ainda, para o vínculo existente entre esta 'Teoria da Individuação em Espinosa' proposta por Deleuze e a formulação de uma ética.

Palavras-chave: quantidade intensiva, potência, individuação, imanência, quantidade extensiva, moral, ética.

I Este estudo introdutório foi apresentado no XII Encontro Nacional de Pesquisa na Graduação em Filosofia em abril de 2009 e as marcas de oralidade eventualmente nele presentes se devem às exigências inerentes à apresentação de uma comunicação. 
O conceito de individualização de Gilles Deleuze: estudo introdutório...

Após a publicação, em I968, de Espinosa e o problema da expressão e, em I970, da primeira versão de Espinosa - filosofia prática, Gilles Deleuze oferece um curso na Universidade de Vincennes entre novembro de I980 e março de I98I dedicado à Ética de Espinosa, recém-editado sob o nome de En medio a Spinoza. ${ }^{2}$ Deleuze trabalha a interpretação já presente em seus escritos - e o faz de forma bastante didática - de que a ontologia de Espinosa é uma ética porque, contrariamente à moral, não se constitui como um sistema do juízo a partir da posição de um 'Uno superior ao ser' ${ }^{3}$ - o Bem -, mas como uma tipologia dos modos de vida considerados do ponto de vista da imanência. ${ }^{4}$ Não mais julgamos uma ação. Ao contrário, situados além de 'bem' e 'mal', fora do terreno do juízo, realizamos uma operação de imanência ao relacionarmos a ação de um ente tanto à sua potência, aumentada ou diminuída com o ato, quanto aos afetos alegres ou tristes por ele sentidos. 'Potência' e 'afetos' dizem respeito ao ente, ao modo de ser, e considerá-lo a partir de uma ética requer, primeiro, que determinemos qual o seu estatuto na filosofia de Espinosa, assunto que ocupa três das quatorze aulas de Deleuze sobre a 'teoria da individuação' na Ética. Não é preciso dizer o quanto a filosofia deleuzeana se vale das formulações por ele atribuídas aos outros filósofos, constituindo-se nas entrelinhas de suas obras monográficas, motivo pelo qual o julgam muitas vezes um mau comentador, porém, um interessante intérprete - correntemente se fala no Hume de Deleuze, no Bergson de Deleuze etc. Michael Hardt, filósofo político estadunidense, refere-se àquilo que diz ser seu 'princípio seletivo':

Como nietzschiano ou como espinosista, Deleuze não aceita todo o Nietzsche ou todo o Espinosa. Se um filósofo apresenta argumentos nos quais Deleuze poderia encontrar

2 Algumas aulas podem ser assistidas ou suas transcrições lidas no site organizado por Richard Pinhas, músico francês e doutor em filosofia pela Sorbonne, cuja tese de doutorado Le rapport entre la schizoanalyse et la science-fiction havia sido orientada por Jean-François Lyotard. Ele foi um dos alunos mais dedicados e presentes nos cursos de Deleuze, e a influência do filósofo pode ser notada não apenas pelo tema de sua tese já mencionada, como pelo nome de sua banda fundada em I968, Schizo, e por sua dedicação à reunião e organização das aulas no site, que, embora bastante completo, ainda não apresenta o curso sobre Espinosa em sua totalidade, este que pode ser encontrado na recente publicação argentina acima referida, à qual nos dedicaremos.

3 Cf. aulas I (25/II/I980) e 2 (2/I2/I980) de En medio a Spinoza.

4 Em Espinosa - Filosofia Prática, Deleuze diz: "Eis, pois, o que a é a Ética, isto é, uma tipologia dos modos de existência imanentes, substitui a Moral, a qual relaciona sempre a existência a valores transcendentes. A moral é o julgamento de Deus, o sistema de julgamento. Mas a Ética desarticula o sistema do julgamento. A oposição de valores (Bem/Mal) é substituída pela diferença qualitativa dos modos de existência (bom/mau)"

(DELEUZE, 2002). 
falhas, ele não os critica, mas simplesmente os deixa fora de sua discussão. Poderia ser dito, então, que Deleuze é um leitor infiel? Certamente que não. Se suas leituras são parciais, elas são, não obstante, muito rigorosas e precisas, com meticuloso cuidado e sensibilidade para tópicos selecionados; aquilo que Deleuze perde em abrangência, ele ganha em intensidade de foco [...]

Cada uma das monografias filosóficas de Deleuze é dirigida para uma questão muito específica, e, visto como um conjunto, o desenvolvimento dessas questões filosóficas revela a evolução de seu pensamento [...] a obra primeira de Deleuze constrói um tipo de história da filosofia muito estranho, no qual os elos articuladores dependem não da historiografia filosófica real, mas da evolução de seu próprio pensamento (HARDT, I996, pp. 22-3).

Não seria forçar os textos dizer que este problema da individuação encontrava suas primeiras formulações já na publicação, em I953, de sua tese de mestrado intitulada Empirismo e subjetividade: ensaio sobre a natureza humana segundo Hume. Nela, Deleuze afirma que David Hume desenvolveu em sua obra não uma questão epistemológica, mas se perguntou sobre a constituição do sujeito: como o sujeito se constitui no dado - o dado tomado como o fluxo de percepções, de imagens? No início, as ideias são associadas sem que haja um sujeito como o suporte de tais associações, ordenando sua conexão, e a subjetividade é produto dos hábitos associativos, é o momento em que das repetições, por uma síntese do tempo, são extraídas normas para a ação futura, acompanhadas pela expectativa de que o que se repetiu no passado seja realizado no futuro uma vez conhecida a causa que o engendrou. A diferença entre o homem e o animal não é essencial; o homem não é definido pela razão: ele devém racional ao ultrapassar o hábito e extrair leis.

Exigindo para a subjetividade que dê conta de seu modo de constituição, Deleuze persegue o programa aberto por Empirismo e subjetividade, que implica uma crítica do sujeito substancial, uma dissolução do eu (moi), em nome do princípio lógico empirista segundo o qual as relações são exteriores a seus termos. Só existem relações de subjetivações, de individuações, sem que não lhe preexistam sujeitos formados, os indivíduos pessoais, os órgãos constituídos (SAUVAGNARGUES, 2004, p. I26; nossa tradução). ${ }^{5}$

5 No original: «En exigeant pour la subjectivité qu'on rende compte de son mode de constitution, Deleuze poursuit le programme ouvert par Empirisme et subjectivité, qui implique une critique du sujet substantiel, une dissolution du moi, au nom du príncipe de logique empiriste selon lequel les relations sont extérieures à leurs termes. Seules existent les relations de subjectivations, d'individuations, sans que ne leur préexistent des sujets formés, des individus personnels, des organes constitués». 
O conceito de individualização de Gilles Deleuze: estudo introdutório...

Como continuação deste programa mencionado por Anne Sauvagnargues, Deleuze em seu curso sobre Espinosa apresenta a 'teoria da individuação' que estaria presente na Ética; estas relações, mencionadas, de subjetivações, de individuações, passam a ser pensadas no interior de uma ontologia da imanência que fornece a Deleuze as condições de propor uma imagem de pensamento em que nada há de transcendente ou transcendental ${ }^{6}$ para assegurar a unidade do sujeito.

Deleuze propõe que consideremos a individualidade segundo três dimensões ou 'capas', a saber: como expressão de um grau de potência, como um sistema de relações de velocidade e repouso entre quantidades intensivas e como um conjunto de partes extensivas exteriores umas às outras. Façamos uma breve análise da primeira delas.

Um indivíduo é antes de tudo uma essência singular, isto é, um grau de potência. A essa essência corresponde uma relação característica; a esse grau de potência corresponde certo poder de ser afetado. Essa relação, finalmente, subsume partes, esse poder de ser afetado é necessariamente preenchido por afecções. Assim, os animais definem-se menos por noções abstratas de gênero e de espécie que pelo poder de serem afetados, pelas afeç̧ões de que são 'capazes', pelas excitações que reagem no limite da sua potência (DELEUZE, 2002, p. 33).

Espinosa é um dos primeiros filósofos ${ }^{7}$ a operar uma identificação entre a essência e a potência dos indivíduos, o que significa que a essência passa a ser definida por aquilo que um indivíduo pode e apenas na medida em que pode, em ato. Isto é romper definitivamente com a tradição aristotélica: para fazer da essência a expressão de uma potência, de um poder que não é senão

$6 \mathrm{Um}$ dos aspectos do elogio de Hume presente em Empirismo e Subjetividade, e talvez o principal, deve-se à concepção de que as relações de ideias são exteriores aos termos associados, isto é, de que não há, no princípio e por princípio, um suporte de tais associações, um sujeito que as regule, uma racionalidade subjacente, uma constância, leis. No princípio, a imaginação é fantasista, delirante; e "nada no pensamento ultrapassa a imaginação, nada é transcendental” (DELEUZE, 200I, p. I26). Deleuze não cansa de nos lembrar que o condicionante não é maior que o condicionado, que os princípios de associação de ideias não condicionam a experiência, mas dela derivam, e que o acordo entre a Natureza e a natureza humana não se explicaria por uma subjetividade transcendental, mas pode ser pensado pela finalidade - ele precisa o sentido deste termo no último capítulo do livro.

7 Deleuze explica que no período do Renascimento o filósofo Nicolás de Cusa havia cunhado o termo possest, uma junção de posse “que é o infinitivo do verbo 'poder' e est, que é a terceira pessoa do verbo 'ser' no presente do indicativo" (En medio a Spinoza, p. 75; nossa tradução). Há a contaminação de um verbo pelo outro e a identificação entre eles: a coisa é o que ela pode em ato, a essência é a potência. 
enquanto está em ato, é necessário não mais pensar nos termos da oposição clássica entre ato e potência, o que implica virar do avesso o conceito de essência. A essência ou a forma não será mais o universal que se diz de muitos indivíduos e que neles existe eternamente, possibilitando, pela sua pertinência não apenas ao logos, mas também ao ser, o conhecimento científico, que nunca é conhecimento do indivíduo, mas do gênero e da espécie. ${ }^{8}$ A essência será, ao contrário e porque é a potência de cada indivíduo, referida somente a ele; Espinosa não fará ciência do universal, mas sua ontologia será uma ética. Vale atentar para o apontamento feito por Deleuze de que o conceito de 'essência' tal como Aristóteles ${ }^{9}$ o compreende, pelo que pode ou não ser existente em ato (devido aos acidentes), ao ser referido ao homem, definindo o que o homem é e é de direito, traz consigo um dever ser: uma moral ou sistema do juízo ${ }^{\text {IO }}$ é instituído.

A definição clássica em Aristóteles: 'o homem é um animal racional'. A essência é o que a coisa é. 'Animal racional' é a essência do homem. Porém, por mais que o homem tenha por essência 'animal racional' ele não tão razoável, não deixa de conduzir-se de maneira irracional. Como ocorre isso? É que a essência do homem, enquanto tal, não está necessariamente realizada. Por quê? Porque o homem não é razão pura, então há acidentes, não deixa de ser desviado. Toda concepção clássica do homem consiste em convidá-lo a se reunir com sua essência porque esta essência é como uma potencialidade que não está necessariamente realizada. E a moral é o processo de realização da essência humana. (...) Então, conduzir-se de maneira razoável, isto é, passar da essência ao

8 "Embora do ponto de vista da realidade só exista o indivíduo", diz Marilena Chauí sobre a filosofia aristotélica, "do ponto de vista da ciência só interessam o gênero e a espécie" (CHAUÍ, p. 378).

9 Não teremos a ocasião de desenvolver isto aqui, mas é interessante remarcar que a crítica a Aristóteles é também fortemente marcada pela influência de Gilbert Simondon, a quem dedicou em ig66 uma resenha intitulada Gilbert Simondon - o indivíduo e sua gênese físico-biológica. Seu contemporâneo, este filósofo francês recusa o esquema 'hilemórfico' aristotélico, segundo o qual o princípio de individuação seria a imposição de uma forma (morphê) a uma matéria. A crítica de Simondon a este esquema é, grosso modo, a de que ele é inadequado para pensar a individuação como processo, como devir, pois parte da compreensão do indivíduo como uma substância, como um, e a partir daí opera uma retrospeç̧ão que não é senão uma abstração, perdendo a dimensão do pré-individual. Aquilo que é anterior à individuação não é ser captado por este pensamento. Ao ser estável, diz Sauvagnargues, "Simondon substitue le concept de métastabilité, différence de potentiel qui induit un changement de phase ; à l'unité Simondon objecte que l'individuation implique un rapport constituant, donc pluriel avec un milieu d'individuation, qui joue comme un milieu métastable; à l'identité, Simondon substitue la rélation première et plurielle, seule capable de rendre compte du devenir" (SAUVAGNARGUES, 2004).

Io Este termo é correntemente empregado por Deleuze em seus textos sobre Espinosa. 
O conceito de individualização de Gilles Deleuze: estudo introdutório...

ato, é a tarefa da moral. Agora, bem, a essência tomada como fim éo valor [grifos e traduções nossos] (DELEUZE, 2008, pág. 7I; nossa tradução). ${ }^{\text {II }}$

O indivíduo passa a ser definido, portanto, pelo que pode e não pelo que é: ${ }^{12}$ a imutabilidade e eternidade que, próprias à essência, são substituídas pela mutabilidade e temporalidade próprias à potência. Gostaria de lembrá-los que a filosofia deleuzeana - e é muito mais dela que tratamos aqui do que de um comentário de Espinosa - é uma ontologia que recusa a noção de 'sujeito' e seus equivalentes religioso, metafísico e científico, tais como as noções de 'alma', 'substância pensante' e 'mente'. Ela é crítica das filosofias da 'representação', para as quais o pensamento se configura, de um lado, em função de um suporte que o exerce, que age, o sujeito, e, de outro, em função de um objeto, sendo os limites entre pensante e pensado claros numa relação de irreversível exterioridade entre eles. Não teremos a ocasião de desenvolver isto na presente exposição, mas esta recusa da noção de 'sujeito', bastante marcada pela crítica já feita por Friedrich Nietzsche ${ }^{13}$ em sua Genealogia da Moral, é intimamente re-

II No original: "La esencia es lo que la cosa es. 'Animal racional' es la esencia del hombre. Pero por más que el hombre tenga por esencia 'animal racional' no es tan razonable, no deja de conducirse de manera irracional. ¿Cómo ocurre eso? Es que la esencia del hombre, en tanto que tal, no está necesariamente realizada. Por qué? Porque el hombre no es razón pura, entonces hay accidentes, no cesa de ser desviado. Toda concepción clásica del hombre consiste en invitarlo a reunirse con su esencia porque esa esencia es como una potencialidad que no está necesariamente realizada. Y la moral es el proceso de la realización de la esencia humana.

(...) Entonces, conducirse de manera razonable, es decir pasar de la esencia al acto, es la tarea de la moral. Ahora bien, la esencia tomada como fin es el valor".

I2 Na Ética Espinosa diz: "O esforço ou a potência da mente é a sua própria essência. A essência da mente, entretanto, afirma [...] apenas aquilo que a mente é e pode, e não o que não é, nem pode. Consequentemente, ela se esforça por imaginar apenas aquilo que afirma ou põe a sua potência de agir" (ESPINOSA, Ética, LIII, P54, D).

I3 Ao se assumir o perspectivismo como ponto de partida, o mundo como não mais do que uma disputa de interpretações, e ao propor a genealogia dos valores como método para pensar as diferentes perspectivas a partir das quais se interpreta o mundo, os diferentes modos de produção de sentido, e se devemos recusar o pensamento do sujeito, livre na exata medida em que é responsável, devedor (em oposição ao credor), o melhor seria, como afirma Nietzsche, um isto pensa, um isto interpreta. Mas o que é este isto que pensa, atribuindo sentido e valor às coisas? Pergunta recorrente no livro Nietzsche et la philosophie de Deleuze: "Quem interpreta?”. A resposta negativa é dada por Nietzsche: "o sujeito não é nada dado, mas algo anexado, colocado por detrás. - É por fim necessário colocar ainda o intérprete por detrás da interpretação? Já isso é poetização, hipótese” (KSA I2, 7). 
lacionada à denúncia de que o pensamento que busca as essências ${ }^{\mathrm{I} 4}$ as converte perigosamente em valores não sem grave prejuízo: a saber, a doença que é a desvalorização do mundo sensível e a instituição de seu julgamento a partir das essências inteligíveis. Ao identificar, pelo recurso a Espinosa, a essência à potência, Deleuze poderá formular um pensamento, desejado desde seus estudos de Henri Bergson, livre da fixidez e identidade próprias à essência, liberado dos procedimentos espacializantes da inteligência, capaz de pensar as passagens no tempo, a diferença, e a subjetividade como processos de individuações.

Veem que a visão moral do mundo está feita de essências [...] Em um mundo ético - tentemos converter - já não há nada disto, não vamos reencontrar nada. É outra paisagem. Espinosa fala muito pouco da essência, mas, para ele, a essência não é 'a essência do homem'. A essência é sempre uma determinação singular. Há essência deste, daquele [...] as essências gerais [...] ou abstratas são ideias confusas (Ibid., p. 7I, 72 ; nossa tradução). ${ }^{15}$

A essência do indivíduo é sua potência que é, por sua vez, parte da potência divina. Há uma substância única imanente a todos os entes ou criaturas com uma infinidade de atributos que exprimem sua essência, seu ser ou realidade. ${ }^{16} \mathrm{Na}$ verdade, Deleuze nos diz em algum lugar ${ }^{17}$ que o que é

Não é, pois, necessário colocar o intérprete, o agente, por detrás da interpretação: que haja um sujeito, isto é uma hipótese, uma perspectiva. Então, quem interpreta? Para responder a esta pergunta, Deleuze funda todo o seu Nietzsche et la philosophie sobre as noções nietzschianas de força e vontade. Ele diz: "As qualidades das forças têm seu princípio na vontade de potência. E se nos perguntamos: 'Quem interpreta? ', nós respondemos a vontade de potência; é a vontade de potência que interpreta" (DELEUZE, p. 60)

I4 Para Nietzsche, o que diz o que uma coisa é não é ela própria, mas algo que se apodera dela e, assim, não se trata de procurar por uma essência, pelo ser-em-si oculto no interior das coisas, mas de substituir esta busca pela pergunta sobre o sentido e o valor das coisas. Por sentido e valor compreendemos as significações externas às coisas mesmas que são doadas por aqueles que se relacionam com elas.

I5 No original: "Ven que la visión moral del mundo está hecha de esencias. (...) En un mundo ético - intentemos convertir - ya no hay nada de todo eso, no vamos a reencontrar nada. Es otro paisaje. Spinoza habla muy a menudo de la esencia, pero para él la esencia jamás es 'la esencia del hombre'. La esencia es siempre una determinación singular. Hay esencia de este, de aquel (...) las esencias generales (...) o abstractas son ideas confusas";

I6 Cf. Spinoza et le problème de l'expression, Introdução.

I7 Em O que éa filosofia, Deleuze diz: "A imanência só é imanente a si mesma, e então toma tudo, absorve o Todo-Uno, e não deixa nada subsistir a que ela poderia ser imanente. Em todo o caso, cada vez que se interpreta a imanência como imanente a Algo, pode-se estar certo que este Algo reintroduz o transcendente" (DELEUZE, I996, p. 63). 
O conceito de individualização de Gilles Deleuze: estudo introdutório...

imanente não é imanente a algo, pois isto já seria transcendência; devemos pensar o imanente como imanente a si mesmo e os atributos e modos como suas expressões... Nós, homens, conhecemos apenas dois destes atributos, o pensamento e a extensão, e este conhecimento só ocorre porque somos, ao mesmo tempo, corpo e alma, ou seja, 'modos' pelos quais estes atributos se exprimem. Não há primazia entre eles, ${ }^{18}$ o pensamento e a extensão, mas um paralelismo, visto que ambos são atributos simultâneos de uma mesma e única substância imanente, Deus, da qual os entes são modificações, modos de ser. Cada modo ou ente, humano ou inumano, caracteriza-se pelo grau de potência divina que nele se expressa. Esta potência é o esforço da mente e o esforço do corpo, simultâneos, para perseverar em seu ser, que Espinosa também designa desejo. ${ }^{19} \mathrm{E}$ porque nós, homens, assim como todos os modos dos atributos divinos, isto é, as 'criaturas', para um vocabulário da transcendência ou processos para uma linguagem da imanência, não temos em nossa essência a causa de nossa existência, nem de nossa duração, ${ }^{20}$ existimos e conservamos nosso ser pela potência divina.

A potência pela qual as coisas singulares e, consequentemente, o homem, conservam seu ser, é a própria potência de Deus, ou seja, da natureza, não enquanto é infinita, mas enquanto pode ser explicada por uma essência humana atual" (ESPINOSA, 2007, LIV, $\left.\mathrm{P}_{4}, \mathrm{D}\right)$.

O modo, aquilo que se individua em meio ao indiferenciado da potência divina, é, portanto, uma de suas partes. Espinosa diz explicitamente "pars potentiae”. ${ }^{21}$ Deleuze remarcará que este termo pars é utilizado pela escolástica como sinônimo de gradus, grau, quantidade intensiva; Espinosa estaria se servindo dele na mesma acepção. Uma parte de potência não deve ser compreendida segundo o atributo da extensão, não é uma quantidade extensiva. Deleuze diz:

I8 Na Ética, Espinosa diz: "[...] o esforço da mente, ou a sua potência de pensar é, por natureza, igual e simultâneo ao esforço do corpo, ou à sua potência de agir” (ESPINOSA, Ética, LIII, P28, D).

I9 Espinosa volta-se contra a ideia de que o sujeito seja provido de uma faculdade de desejar.

20 Espinosa diz na Ética: "(..) Deus é não apenas a causa pela qual as coisas começam a existir, mas também pela qual perseveram em seu existir, ou seja (para usar um termo escolástico), Deus é a causa do ser das coisas. Pois, quer as coisas existam, quer não, toda vez que consideramos sua essência, descobrimos que ela não envolve nem a existência nem a duração. E por isso, não é sua essência que pode ser a causa de sua existência, nem de sua duração, mas apenas Deus, cuja natureza é a única à qual pertence o existir" (ESPINOSA, Ética, Livro I, P24, G).

2I Cf. En medio a Espinosa, p. 240.

I64 
[...] uma essência é um grau de potência. Isto é, se é uma quantidade, é uma quantidade intensiva. Uma quantidade intensiva não é em nada como uma quantidade extensiva. Uma quantidade intensiva é inseparável de um umbral, isto é, que já é em si mesma uma diferença. A quantidade intensiva está feita de diferenças (DELEUZE, 2008, pág. 240; nossa tradução). ${ }^{22}$

Uma quantidade intensiva é feita de diferenças; uma individualidade ou um modo é uma parte de potência que se diferencia em meio à potência vital, à natureza. Tocamos sumariamente neste ponto da análise nos conceitos de 'potência', 'quantidade' e 'diferença', recorrentes na filosofia de Deleuze desde a publicação de Nietzsche et la philosophie. Vimos até agora que uma das dimensões constitutivas do indivíduo é a potência. O modo é uma parte da potência divina, é uma intensidade, embora a substância seja ela mesma indivisível. Há ainda outras duas dimensões a serem consideradas, e uma delas concerne à relação.

A esta intensidade que caracteriza o indivíduo correspondem uma relação de movimento e repouso ou de velocidade e lentidão e múltiplas partes exteriores umas às outras, cuja organização se deve à submissão a esta relação. É por ser composto por partes que o modo pode ser dividido. Será então importante examinar qual o estatuto destas partes ou corpos simples que constituem os corpos compostos ao entrarem nas relações que caracterizam suas essências - e é neste ponto da análise que tocaremos conceitos que frequentemente presentes na filosofia de Deleuze, talvez tornados mais claros com sua remissão à visada do filósofo ao século XVII. Seriam, pois, estas partes simples quantidades extensivas, mensuráveis, exteriores umas às outras? Ou seriam elas outro tipo de quantidade, cuja mensuração só é possível pelo estabelecimento de uma correspondência com as quantidades extensas, como ocorre com a temperatura em um termômetro, que só pode ser medida a partir da correspondência com o movimento das partículas de mercúrio? Este outro tipo de quantidade Deleuze denomina intensiva; e sua oposição à interpretação de Martial Guéroult, filósofo francês, a respeito do que seriam os corpos simples a partir dos quais se formam os compostos, passa justamente pela consideração deste outro tipo de quantidade.

Há uma aparente contradição na Ética com a qual ambos os filósofos trabalham. Na proposição I3 da parte II da Ética, no lema I, lê-se sobre os corpos simples que eles "se distinguem entre si pelo movimento e pelo repouso, pela

22 No original: "[...] la esencia es un grado de potencia. Es decir, si es una cantidad, es una cantidad intensiva. Una cantidad intensiva no es para nada como una cantidad extensiva. Una cantidad intensiva es inseparable de un umbral, es decir que es ya en si misma una diferencia. La cantidad intensiva está hecha de diferencias". 
O conceito de individualização de Gilles Deleuze: estudo introdutório...

velocidade e pela lentidão, e não pela substância” (ESPINOSA, 2008, LII, Pı3, LI), afirmativa também encontrada no axioma $2,{ }^{23}$ ao passo que no axioma 3 da mesma, Espinosa, ao pensar a ação de um corpo composto sobre o outro, diz que eles são compostos por partes (os corpos simples) com 'superfícies' justapostas umas às outras, o que nos levaria a pensar que os corpos simples são distintos um dos outros por sua figura e pelo seu tamanho, isto é, por sua magnitude (e não pela velocidade e lentidão, como constava no lema I).

Quanto maiores ou menores são as superfícies mediante as quais as partes de um indivíduo, ou seja, de um corpo composto, se justapõem, tanto mais ou menos dificilmente, de maneira respectiva, elas podem ser forçadas a mudarem de posição e, como consequência, tanto mais ou menos dificilmente pode-se fazer que este indivíduo adquira outra figura [...] (ESPINOSA, 2008, LII, Pi3, A3; itálico e negrito nossos). ${ }^{24}$

Resumo rapidamente a apresentação ${ }^{25}$ de Deleuze sobre esta contradição: da afirmação de que os corpos simples ${ }^{26}$ só se distinguem pela velocidade e lentidão, pelo movimento e pelo repouso, concluiríamos: I) ou que todos os corpos simples são idênticos no tamanho e na figura e não há diferença entre eles; 2) ou que apesar de diferentes em suas magnitudes, esta diferença não é operatória porque são muito pequenos; 3) ou que eles não têm magnitude. Mas teríamos que conciliar qualquer uma destas possibilidades com a afirmação de que os corpos simples se aplicam uns sobre os outros segundo superfícies, o que significa que eles têm magnitude. A fim de resolver este problema que está no cerne da teoria da individuação, os dois filósofos franceses lançam o olhar em direção aos diferentes caminhos percorridos na matemática e na física do século XVII. Guéroult considera que apesar de distintos em suas figuras e

23 "Quando um corpo em movimento se choca com outro que está em repouso e que ele não pode deslocar, ele é rebatido de maneira tal que continua se movendo, e o ângulo formado pela linha do movimento de seu rebatimento com a superfície do corpo em repouso, com o qual se chocou, será igual ao ângulo formado pela linha de incidência do movimento com este mesmo plano. Isso quanto aos corpos mais simples, aqueles que se distinguem entre si apenas pelo movimento e pelo repouso, pela velocidade e pela lentidão" (ESPINOSA, 2007, p. IOI).

24 Ver ainda a definição da Proposição I3: "Quando corpos quaisquer, de grandeza [latim: magnitudinis] igual ou diferente, são forçados, por outros corpos, a sejustaporem [...]” (ESPINOSA, 2008, LII, PI3, Definição; itálico nossos).

25 Cf. Aula Io (DELEUZE, 2008).

26 O filósofo aplica esta afirmação aos corpos simples, visto que os corpos compostos se distinguem, em primeiro lugar e sob um aspecto sensível, pelas diferenças de figura e de tamanho; donde Deleuze conclui que Espinosa não poderia estar se referindo a eles. 
tamanhos, porque os corpos simples são muito pequenos, esta distinção não é operatória: ${ }^{27}$ é pela velocidade e lentidão que se distinguem. O pano de fundo desta concepção é a teoria dos pêndulos, e o filósofo pensará os corpos simples como matérias que vibram: os pêndulos têm magnitudes, mas no cálculo de sua oscilação, elas não entram como variáveis.

[...] a hipótese de Guéroult parece ter um sentido muito interessante porque no século XVII o estudo pela física dos corpos giratórios e dos pêndulos está muito avançado. Em particular, fundou uma distinção entre os pêndulos simples e os pêndulos compostos. Vem que desde então a hipótese de Guéroult será convertida nesta: cada corpo simples é um pêndulo simples e o indivíduo, que possui uma infinidade de corpos simples, é um pêndulo composto. Seríamos todos pêndulos compostos ou corpos giratórios [...] Vem então que a resposta de Guéroult é que a relação de movimento e de repouso deve ser compreendida como a vibração do pêndulo simples. É por isso, ademais, que Guéroult tem necessidade de afirmar que em Espinosa os corpos simples têm, apesar de tudo, uma figura e um tamanho. Suponham, ao contrário - e não digo em absoluto que eu tenha razão - que os corpos simples são, com efeito, infinitamente pequenos, isto é, que não têm nem figura, nem tamanho. Aqui o modelo do pêndulo simples não pode funcionar (Ibid., pp. 390-I; nossa tradução). ${ }^{28}$

Já Deleuze pensará os corpos simples como elementos que tendem a desaparecer de uma relação que, no entanto, sem eles subsiste: a relação diferencial. Para pensá-lo Deleuze crê ser necessária a retomada do problema principal do

27 Em En Medio de Spinoza, Deleuze diz: "Gueroult quiere decir: 'Atención, esos corpos muy simples sólo se distinguen por el movimiento y por el reposo, pero eso no quiere decir que tengan igual figura e igual tamaño. Quiere decir, a lo sumo, que sus diferencias de figura y tamaño no sirven, no son operatorias al nivel de los cuerpos muy simples. Ellas sólo tomarán importancia por relación a los cuerpos compuestos" (DELEUZE, 2008, pág. 337).

28 No original: "(...) la hipótesis de Gueroult parece tomar un sentido muy interesante porque en el siglo XVII la física tiene muy avanzado el estudio de los cuerpos giratorios y de los péndulos. En particular ha fundado una distinción entre los péndulos simples y los péndulos compuestos. Ven que desde entonces la hipótesis de Gueroult se convertirá en esta: cada cuerpo simple es un péndulo simple y el individuo, que posee una infinidad de cuerpos simples, es un péndulo compuesto. Seríamos todos péndulos compuestos o discos giratorios". "Ven entonces que la respuesta de Gueroult es que la relación de movimiento y de reposo debe comprenderse como la vibración del péndulo simple. Es por eso además que Gueroult tiene necesidad de afirmar que en Spinoza los cuerpos muy simples tienen a pesar de todo una figura y un tamaño. Supongan por el contrario - y no digo en absoluto que yo tenga razón - que los cuerpos simples son en efecto infinitamente pequeños, es decir que no tienen ni figura ni tamaño. Aquí el modelo del péndulo simple no puede funcionar”. 
O conceito de individualização de Gilles Deleuze: estudo introdutório...

século XVII: a questão do infinito atual. Suas objeções ao modelo do pêndulo proposto por Guéroult são a de que Espinosa nunca o menciona, nem sequer em suas cartas, e a de que ele não dá conta deste problema do homem que é estar situado entre dois infinitos atuais, o infinitamente grande e o infinitamente pequeno, representados vagamente ao olhar para o céu e para o microscópio. Uma coisa, diz Deleuze, "(...) não é mais que uma ponte entre estes dois infinitos, se vocês querem, um microinfinito e um macroinfinito. O finito é precisamente como a comunicação entre estes dois infinitos” (Ibid., pág. 362). ${ }^{29}$

O problema dos dois infinitos é um dos fundamentos do cálculo diferencial. Não temos condições de entrar em seus pormenores nesta exposição, mas o que nos interessa é que o cálculo diferencial é uma igualdade entre, por um lado, uma relação cujos termos estão em vias de desaparecimento, elementos que tendem sempre ao infinitamente pequeno e não podem ser designados por números, e, por outro, um termo finito, embora variável, ao qual esta relação se iguala. ${ }^{30}$ Há

29 No original: “(...) no es más que un puente entre esos dos infinitos, si ustedes quieren, un microinfinito y un macro-infinito. Lo finito es precisamente como la comunicación entre esos dos infinitos". 30 Para nos aproximarmos melhor do significado desta proposição, resumo rapidamente a explicação de Deleuze na aula de número I2. Consideremos, primeiramente, uma relação fracionária, 2/3, por exemplo. Ela não é um número, é um complexo numérico, uma relação que se estabelece entre dois números: 2/3 é uma relação de divisão do número 2 pelo 3 ou de multiplicação do 3 pelo 2, que tratamos como um número embora não haja "número asignable que multiplicado por 3 dé 2" (DELEUZE, En medio de Spinoza, pág. 392). Já uma relação algébrica é aquela que se estabelece não entre dois números, mas entre duas variáveis: x/y. Há uma independência em relação aos números, pois a relação subsiste apesar de seus termos $x$ e $y$ serem variáveis.

"En una relación algebraica no tengo necessidad de um valor singular, lo cual no quita que mis términos continúen teniendo un valor especificable. La relación es efectivamente independiente de todo valor particular de la variable, pero no és independiente de un valor determinable” (Ibidem, pág. 393).

A relação diferencial é aquela que se funda entre duas relações de infinitamente pequenos. Há uma primeira relação em que, qualquer que seja o valor de $y$ (eixo das ordenadas), dy será sempre menor, pois é uma quantidade evanescente; dy em relação a y é sempre igual a o. Há uma segunda relação na qual com $x$ (eixo das abscissas) acontece o mesmo: qualquer que seja o valor de $x$, porque $d x$ é uma quantidade evanescente, $d x$ relacionado a x é zero. Se relaciono $d y$ a $d x$, tenho $d y / d x$ que é igual a $0 / 0$. Mas $O / O$ não é o, é z, uma variável que nos diz algo sobre a tangente trigonométrica, e esta é algo finito. Uma relação entre quantidades evanescentes, dx e dy, não nos diz nada sobre x e y, mas sobre z. Deleuze diz: "dy no es nada por relación a $y, d x$ no es nada por relación a $x$, pero $d y$ sobre $d x$ no se anulan. Entonces la relación subsiste. La relación diferencial se presentará como la subsistencia de la relación cuando los términos se desvanecen" (Ibidem, pág. 368). "Cuando los términos de la relación - x y y - se desvanecen y devienen dx y dy, la relación subsiste porque tiende hacia un limite z" (Ibidem, pág. 394). 
uma relação que se preserva no desvanecimento de seus elementos e ela é igual a uma variável finita, não evanescente: seu limite.

(...) a relação que é independente dos termos vai designar um terceiro termo, vai servir para a medida e para a determinação de um terceiro termo: a tangente trigonométrica. Posso dizer, neste sentido, que a relação infinita - isto é, a relação entre o infinitamente pequeno - remete a algo finito. A imanência mútua do infinito e da relação está no finito (Ibid., pág. 369; nossa tradução). ${ }^{3 \mathrm{r}}$

Se, na trigonometria, este termo finito variável é a tangente trigonométrica, na filosofia de Deleuze ele é tudo o que é finito e corpóreo e que só o é porque é sustentado por relações que se articulam rumo ao infinitamente pequeno e que não encontram termos últimos, elementos atômicos: Deleuze recusa o atomismo.

Os corpos simples cujo estatuto procurávamos definir seriam estes elementos evanescentes, e que só são perceptíveis nos conjunto infinito de que fazem parte, nas relações das quais são termos e em que se articulam, por sua vez, com outras relações que, por sua vez, se articulam com outras... Todo o corpo, se analisado segundo as relações que os constituem, pode ser decomposto em relações mais simples, e os termos destas relações devem ser pensados como pertencentes a um conjunto infinito, a um conjunto de infinitamente pequenos infinito. É porque os corpos simples são elementos que tendem ao infinito que estamos impossibilitados de chegar a um ponto último de matéria. Eles só podem ser considerados em conjuntos: "eles vão por infinidades" (Ibid., pág. 340), diz Deleuze. E, se os tomarmos assim, poderemos compreender porque é que se diferenciam por velocidade e lentidão, movimento e repouso, ao mesmo tempo em que se aplicam uns sobre os outros segundo superfícies: não é um corpo simples que constituirá matéria e terá uma magnitude, mas um conjunto infinito de corpos simples. Mais precisamente, não devemos falar em um corpo simples, mas apenas em uma infinidade de corpos simples que possui, ela, uma figura e um tamanho. "Uma infinidade é irredutível ao número", diz.

Não faltam exemplos concretos na exposição feita por Deleuze: se pensarmos no sangue, que é material, finito, ele é composto por uma relação de movimento e repouso, de velocidade e lentidão entre suas partes. O 'quilo' e a 'linfa' são

3I No original: "(...) la relación que es independiente de los términos va a designar un tercer término, va a servir a la medida y a la determinación de un tercer término: la tangente trigonométrica. Puedo decir, en este sentido, que la relación infinita - es decir la relación entre lo infinitamente pequeño - remite a algo finito. La inmanencia mutua de lo infinito y de la relación está en lo finito”. 
O conceito de individualização de Gilles Deleuze: estudo introdutório...

estas partes para o pensamento do século XVII, ${ }^{32}$ também caracterizadas por determinada relação entre suas partes.

E sobre isso ele explica que o quilo e a linfa são eles mesmos dois sistemas de relações entre partículas, não são corpos simples (Ibid; pág. I39; nossa tradução). ${ }^{33}$

Isto não nos leva a prolongar a análise indefinidamente. O quilo e a linfa devem ser compreendidos como conjuntos infinitos de infinitamente pequenos. O sangue é finito, extenso, assim como suas partes: o quilo e a linfa têm contornos, magnitudes. Não é um corpo simples que constituirá matéria e terá uma magnitude, mas um conjunto infinito de corpos simples. Ghegamos, assim, mais perto de compreender porque é que eles só se diferenciam por velocidade e lentidão, movimento e repouso e, ao mesmo tempo, aplicam-se uns sobre os outros segundo superfícies.

Se retomam uma das cartas de Spinoza, de que me servi muito, o que quer nos dizer sobre o sangue e seus componentes, o quilo e a linfa? Nos diz que há corpúsculos de quilo, ou melhor, que o quilo é um conjunto infinito de corpos muito simples. A linfa é um conjunto infinito de corpos muito simples. O que distingue os dois conjuntos infinitos? A relação diferencial. [...] Esta relação diferencial tende em direção a um limite: o sangue. O quilo e a linfa compõem o sangue (Ibid., pág. 395; nossa tradução). ${ }^{34}$

Os corpos simples de que falávamos são os elementos infinitamente pequenos, evanescentes. Dizíamos que só podemos pensá-los a partir da consideração do conjunto infinito de que fazem parte, mas de fato, só podemos pensá-los na relação que se estabelece entre dois conjuntos infinitos de infinitamente pequenos, na relação que se estabelece, por exemplo, entre o corpúsculo de quilo e o corpúsculo de linfa. Os infinitamente pequenos

32 Deleuze estabelece uma analogia entre o quilo e a linfa e os glóbulos brancos e vermelhos, ainda que diga ser grosseira. Cf. aula 5 .

33 No original: "Y sobre eso él explica que el quilo y la linfa son ellos mismos dos sistemas de relaciones entre partículas, no son cuerpos simples" (Ibidem, pág. I39).

34 No original: "Si retoman una de las cartas de Spinoza, de la que me he servido mucho, ¿qué nos quiere decir sobre la sangre y sus componentes, el quilo y la linfa? Nos dice que hay corpúsculos de quilo, o más bien, que el quilo es un conjunto infinito de cuerpos muy simples. La linfa es un conjunto infinito de cuerpos muy simples. ¿Qué distingue a los dos conjuntos infinitos? La relación diferencial. [...] Esta relación diferencial tiende hacia un limite: la sangre. El quilo y la linfa componen la sangre”. 
não existem independentemente da relação diferencial entre conjuntos de que são partes evanescentes. A diferença, trabalhada ao longo de toda a obra de Deleuze, aparece como um princípio de individuação: os elementos que constituem um conjunto só são elementos na relação de diferença que os constitui. E esta diferença é uma diferença entre potências, ${ }^{35}$ quantidades intensivas.

Temos, portanto, duas dimensões: às quantidades extensivas das partes que se aplicam umas sobre as outras constituindo um corpo composto correspondem quantidades intensivas próprias aos conjuntos que compõem o sistema de relações característico do corpo. É só assim que poderemos compreender a definição de um indivíduo, ao mesmo tempo, como um conjunto de elementos materiais exteriores uns aos outros e por uma potência.

\begin{abstract}
A individuação para Espinosa não é qualitativa nem quantitativa - no sentido da quantidade extensiva - é intensiva. Portanto, se tento agrupar em uma mesma fórmula as três dimensões da individualidade, diria que: a) um indivíduo é uma parte intensiva, isto é, um grau de potência; b) enquanto grau de potência se expressa em uma relação de movimento e de repouso, de velocidade e lentidão; c) um número muito grande de partes extensivas pertence ao indivíduo sob essa relação (Ibid., pág. 329; negrito nosso). ${ }^{36}$
\end{abstract}

Fomos trazidos ao problema da individuação devido à questão ética apresentada rapidamente no início da introdução. Os pares de valores Bem e Mal são substituídos na Ética de Espinosa pelos valores 'bom' e 'mau', possibilitando que uma individualidade seja avaliada de forma imanente, isto é, considerado apenas o aumento ou a diminuição de sua potência a partir de ações praticadas em um meio pleno de outras individualidades, outras potências, outras quantidades intensivas, afetando-as e delas se distinguindo. $\mathrm{O}$ plano da imanência nos leva a pensar a experiência segundo o conceito de afeto e a variação de potência é sentida pelos existentes segundo duas polaridades de afetos qualitativamente distintas: a tristeza e a alegria. Podemos opor os modos de vida segundo a consideração dos afetos que neles predominam, substituindo

35 Cf. En medio a Spinoza, p. 395.

36 No original: "La individuación para Spinoza no es ni cualitativa ni cuantitativa - en el sentido de cantidad extensiva-. Es intensiva. Por tanto, si intento agrupar en una misma fórmula las tres dimensiones de la individualidad, diría que: a) un individuo es una parte intensiva, es decir, un grado de potencia; b) en tanto que grado de potencia se expresan en una relación de movimiento y de reposo, de velocidad y lentitud; c) un número muy grande de partes extensivas pertenecen al individuo bajo esa relación”. 
O conceito de individualização de Gilles Deleuze: estudo introdutório...

o julgamento moral pela pergunta ética que relaciona o modo de existência à sua ação ou à sua fala: "Como tem que ser para dizer ou fazer isso? Que maneira de ser implica?". Deleuze diz:

(...) há duas diferenças fundamentais entre a moral e a ética, isto é, entre a arte do bem e do mal e a disciplina do bem e do mal. [...] o bom e o mal implicam em primeiro lugar que há entre os entes, isto é, entre os existentes, uma distinção quantitativa. [...] A ética é fundamentalmente quantitativa. Minha segunda ideia é que o bom e o mal designam uma oposição qualitativa entre os modos de existência. Distinção quantitativa entre os entes, oposição qualitativa entre os modos de existência (Ibid., pág. 64). ${ }^{37}$

E reto ma a ideia já presente em sua leitura de Nietzsche, de que "sempre tem os afetos que merecem em virtude de vosso modo de existência" (DELEUZE, 2008, pág. 463). ${ }^{38}$

\section{Referências bibliográficas.}

DELEUZE, G. (200I). Empirismo e subjetividade: ensaio sobre a natureza humana segundo Hume. São Paulo: 34 .

. (2008). En medio de Spinoza. Buenos Aires: Cactus.

(2002). Espinosa - filosofia prática. São Paulo: Escuta.

Nietzsche et la philosophie. Paris: PUF.

(I996). O que é a filosofia? São Paulo: Editora 34.

ESPINOSA, B. (2007). Ética. São Paulo: Autêntica.

37 No original: "(...) hay dos diferencias fundamentales entre la moral y la ética, es decir, entre el arte de lo bueno y lo malo y la disciplina del bien y del mal. [...] lo bueno y lo malo implican en primer lugar que hay entre los entes, es decir, entre los existentes, una distinción cuantitativa. [...] La ética es fundamentalmente cuantitativa. Mi segunda Idea es que lo bueno y lo malo designan una oposición cualitativa entre los modos de existencia. Distinción cuantitativa entre los entes, oposición cualitativa entre los modos de existencia".

38 No original: "siempre tienen los afectos que merecen en virtud de vuestro modo de existencia". 
HARDT, M. (I996). Gilles Deleuze: um aprendizado em filosofia. São Paulo: 34.

SAUVAGNARGUES, A. (2004). Deleuze. De l'animal 'a l'art. In: La philosophie de Deleuze (pp. II7-227). Paris: Quadrige.

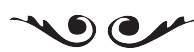

Bruna Martins Coelho é graduada em Filosofia pela USP.

E-mail: bruna.brunilda@gmail.com 